\title{
Rehabilitation for motor functional neurological disorder: a follow-up study of 185 patients
}

\author{
Reabilitação para transtorno neurológico funcional \\ motor: um estudo de acompanhamento de 185 casos
}

Renata Valladão THEUER?', Simone Vilela Nunes NEVES², Ana Paula Silva CHAMPS ${ }^{3}$

\begin{abstract}
Background: Motor functional neurological disorder (mFND) is a common and disabling condition. There are no evidence-based guidelines for treatment. Long-term outcome is often poor. This study describes the epidemiological profile, symptom pattern and outcome of patients admitted to the Belo Horizonte unit of the SARAH Network of Rehabilitation Hospitals from 1997 to 2018 with functional motor symptoms resulting from functional neurological disorder. Methods: This retrospective study reviewed data from 185 patients who met inclusion criteria for mFND. Diagnoses were made by multiple professionals in the presence of positive signs and excluding other neurological and systemic conditions. Results: $75.1 \%$ were women; $48.3 \%$ were receiving social security benefits. The youngest was 3 years old, the oldest 69. $23.8 \%$ were in wheelchairs, $77.2 \%$ had psychiatric disorders, $69.7 \%$ participated in rehabilitation programs and, among them, $70 \%$ improved. Conclusion: Participation in rehabilitation is beneficial for patients with mFND. Symptoms lasting for less than 30 days and aged less than 18 years had better outcomes $(p<0.001)$.
\end{abstract}

Keywords: Nervous System Diseases; Conversion Disorder; Movement Disorders; Rehabilitation.

\section{RESUMO}

Introdução: Alterações motoras decorrentes de Transtorno Neurológico Funcional (TNF) são comuns, incapacitantes e com prognóstico ruim. Não há protocolos de tratamento baseado em evidências. Esse estudo descreve o perfil epidemiológico, os sintomas e a evolução de pacientes com alterações motoras decorrentes de Transtorno Neurológico Funcional (TNF) admitidos na unidade de Belo Horizonte da Rede SARAH de Hospitais de Reabilitação no período de 1997 a 2018. Métodos: Este estudo retrospectivo analisou dados de 185 pacientes que atenderam aos critérios de inclusão para TNF. Os diagnósticos foram realizados por múltiplos profissionais considerando a presença de sinais positivos e a exclusão de outras condições neurológicas e sistêmicas. Resultados: $75,1 \%$ eram mulheres; 48,3\% estavam recebendo benefícios previdenciários. 0 indivíduo mais jovem tinha 3 anos de idade, e o mais velho, 69 anos. $23,8 \%$ usavam cadeira de rodas, $77,2 \%$ apresentavam desordens psiquiátricas, $69,7 \%$ tinham participado do programa de reabilitação e, dentre esses, $70 \%$ apresentaram melhora dos sintomas. Conclusão: 0 processo de reabilitação é benéfico para pacientes com TNF. Pacientes menores de 18 anos de idade e com sintomas de evolução com duração inferior a 30 dias apresentaram melhores resultados no tratamento $(p<0,001)$.

Palavras-chave: Doenças do Sistema Nervoso; Transtorno Conversivo; Transtornos do Movimento; Reabilitação.

Over time, disorders that cause unstable body motion and control, inconsistent and incongruent with any recognizable neurological disease, have received a variety of names, such as hysterical paraplegia, psychogenic movement disorder and conversion disorder ${ }^{1}$. In this paper, we use the term functional neurological disorder (FND) ${ }^{2}$.

FND is heterogeneous. The present report mainly focuses on FND presenting with motor symptoms (mFND), such as dystonia, paralysis, tremor, imbalance, etc. Usually, it is accompanied by a wide range of other somatic features, such as dizziness, headaches and non-epileptic seizures ${ }^{3}$.

Previously, this diagnosis of $\mathrm{mFND}$ was made only in the absence of a medical explanation for the symptoms, on the basis of history features alone. Currently, the diagnosis relies in the presence of positive signs: multiple symptoms and other functional symptoms (chronic fatigue, fibromyalgia, and asthma), clear evidence of physical signs of internal inconsistency such as Hoover's sign, gait changes, fluctuation

1SARAH, Departamento de Psicologia, Belo Horizonte MG, Brazil.

2SARAH, Departamento de Neurologia, Belo Horizonte MG, Brazil.

${ }^{3}$ SARAH, Departamento de Medicina, Belo Horizonte MG, Brazil.

Renata Valladão THEUER (D) https://orcid.org/0000-0002-4390-2579; Simone Vilela Nunes NEVES (D) https://orcid.org/0000-0001-5584-0144; Ana Paula Silva CHAMPS (iD) https://orcid.org/0000-0003-2557-8813

Correspondence: Renata ValladãoTheuer; E-mail: renatabhz@sarah.br

Conflict of interest: There is no conflict of interest to declare.

Received on October 20, 2019; Received in its final form on December 24, 2019; Accepted on January 16, 2020. 
of symptoms, presentations incompatible with scientific knowledge, and lack of positive findings in imaging and laboratory studies ${ }^{4}$.

By definition, mFND is a condition that can resemble other neurological conditions, so the accuracy of diagnosis must be reassured. Studies conducted in the 1960s reported a $29 \%$ rate of misdiagnosis. Currently, after substantial scientific advances and the development of more accurate criteria, the rate of false positives has dropped to $4 \%{ }^{1,5}$.

While the complex relations between mind and body motion remain obscure, the burden of mFND is high; FND represents an important socioeconomic challenge accounting for between 1 in 20 and 1 in 10 neurologic presentations. Several studies have reported a high rate of unemployed patients, ranging from 43 to $89 \%$ 6.7. Symptoms persistence may alter quality of life to the same degree of a severe neurological condition such as Parkinson's disease ${ }^{8,9}$.

Studies indicate that mFND disturbances require a multidisciplinary treatment approach. The importance of how to communicate the problem and implement a highly integrated treatment has been emphasized. Overall, studies indicate that the evolution of motor alterations secondary to functional neurological disorder has a poor prognosis. A recent review of 22 studies on the subject suggests that 33 to $66 \%$ of patients evolved without modification or worsening of symptoms ${ }^{4,10}$. Factors correlated with better prognosis are related to good physical health, negative psychiatric history, and a history of acute onset and short duration, triggered by a marked stress factor ${ }^{6}$.

In this paper we describe the epidemiological profile, symptom pattern, and outcome of patients with motor alterations resulting from functional neurological disorder admitted to the Belo Horizonte unit of the SARAH Network of Rehabilitation Hospitals from January 1997 to June 2018.

\section{METHODS}

This is a retrospective chart review based on electronic records of patients admitted to the SARAH Rehabilitation Hospital in Belo Horizonte from January 1997 to June 2018.

The search for electronic records was performed from the records of the rehabilitation team: neurologists, clinicians, psychiatrists, psychologists, and physiotherapists, among others. Somatization disorder (F-45 ICD10) and the terms in Portuguese "conversão" (conversion), "psicogênico" (psychogenic), "somático" (somatic) and "somatoforme" (somatoform) were searched. This search resulted in 1,015 records.

Exclusion criteria were patients who came for just an evaluation and dropped out of care. Patients with sudden and transient conditions, usually blackouts, vertigo and paralysis; patients with painful disorders, in which pain was the main symptom without any change in movement, and patients with known neurological diseases whose symptoms are exacerbated by psychic issues. Additionally, $10 \%$ of the patients who had mFND as one of the diagnostic hypotheses in their first evaluation at the hospital, ultimately had the diagnosis discarded throughout medical evaluation, they were also eliminated from the sample.

In the end, 185 patients were selected. All of them had motor changes in the lower and/or upper limbs and/ or trunk with and without accompanying gait changes. The diagnosis was not a diagnosis of exclusion. All patients underwent neurological exams and $86 \%$ were examined by more than three experienced rehabilitation professionals. All patients met the diagnostic criteria for mFND: historical background, usually with multiple somatizations, variability of severity and distribution of symptoms; clinical examination presenting atypical, incongruous and inconsistent motor patterns; laboratory and image findings incompatible with organic disease ${ }^{2}$.

Clinical characteristics, risk factors, psychiatric comorbidities, treatment and prognoses of the selected patients were delineated.

The age of patients was considered as the age at which symptoms appeared and not age upon admission for rehabilitation care. The endpoint was the date when patients had the last visit or the end of follow-up in June 2018, whichever occurred first. All clinical diagnostic and physical evaluation criteria followed standardized international guidelines.

Independent variables were:

- Socio-epidemiological: sex, age, marital status, and level of education.

- Lifestyle: alcohol or tobacco consumption or drug use.

- Clinical: presence of pain and comorbidities such as psychiatric disturbances, lower urinary tract dysfunction, blackout episodes.; and

- Physical signs: weakness or paralyses and the use of some type of support for locomotion.

Outcome was considered as: remission of symptoms, moderate improvement (50\%) or marked improvement (75\%), patients who had periods of improvement and worsening, and patients who got worse. Moderate and marked improvements were defined considering pain reduction, increased mobility, participation in daily activities and working status.

\section{Statistical analysis}

After data collection, the records were entered into Excel spreadsheets. The description of patients' epidemiological, sociodemographic and clinical characteristics was made in the same program. Next, an exploratory data analysis was performed with the Statistical Package for the Social Sciences (SPSS) 20.0 to examine the characteristics of the population studied. The chi-square and Fisher's exact tests were used to compare the proportions of the categorical variables. For comparisons between means and medians, 
the nonpaired and Mann-Whitney t tests, respectively, were used. Two-tailed significance level considered was $\mathrm{p}<0.05$.

\section{RESULTS}

In the SARAH unit of the Belo Horizonte, the number of patients diagnosed with mFND has been growing. Although it is increasing, this diagnosis with no other neurological condition represents less than $0.5 \%$ of all diagnoses made per year.

Among the 185 patients of our sample, there was a predominance of women $(75.1 \%), 50.8 \%$ were married, 92 patients $(49.7 \%)$ had gone to school nine years or more, which is a higher level of education than the average of the hospital population. The youngest patient was 3 years old, and the oldest patient was 69 years old. The mean age of symptoms onset was 28.8 years ( $\mathrm{SD} \pm 13.3$ years). One-quarter of the subjects were less than 18 years of age at the time of first symptom. Among those, mean age was 11.2 years (SD 3.6). 80\% of them received inpatient treatment, always accompanied by at least one of their parents.

Associated psychiatric conditions, mainly depression and anxiety, were identified in $77.2 \%$ of the patients. There were no cases of alcoholism or drug addiction, and only $7 \%$ of patients used tobacco (Table 1).

In most cases (58.4\%), symptoms started abruptly, in less than 24 hours, and in $45.4 \%$ of the cases, the initial manifestation was pain. Upon physical evaluation, $81.1 \%$ of patients showed weakness in the lower limbs, with $23.8 \%$ requiring the use of wheelchairs; $50 \%$ had upper limb involvement. In total, $22.2 \%$ of patients had balance impairment, $18.9 \%$ had tremors, 2,7\% had dystonia and 54.6\% had associated changes in sensitivity. A total of $19.5 \%$ had blackout episodes, $29 \%$ had dizziness, $29.2 \%$ had abnormal functioning of the lower urinary tract, manifesting as voiding dysfunction, storage dysfunction, or both. In addition, $36.2 \%$ of the sample had migraines.

All patients were communicated about the diagnosis and $30.3 \%$ of them do not participate in the rehabilitation program. Those were followed up for a period that ranged from one month to two years, with median of six months.

Those who did undergo rehabilitation were followed up for a period ranging from one month to 12 years, with median of 13 months (DP 46). Among them, 53.4\% did so on an inpatient basis. SARAH receives patients from different cities and states of Brazil. Being in or outpatient is a decision made mainly based on the distance of patient's home and it was not a significant outcome variable.

The rehabilitation package may include physical and occupational activities, nursing and nutrition guidance, psychiatric and psychological support. The program is developed according to the demands and availability of each patient. In our sample, all patients received physical therapy and 140 patients underwent at least one mental health evaluation (psychiatrist and/or psychologist). Family participation is always encouraged.

In the follow-up, $35.9 \%$ did not have any changes in status, and $8.2 \%$ continued to use a wheelchair. A total of $21.2 \%$ of patients had complete remission of their symptoms, and $3.2 \%$ of them had spontaneous remission. $33,7 \%$ had moderate or

Table 1. Clinical and epidemiological profiles of 185 patients with $\mathrm{mFND}$.

\begin{tabular}{|c|c|}
\hline Features & $\mathrm{n}(\%)$ \\
\hline \multicolumn{2}{|l|}{ Sex } \\
\hline Female & $139(75.1 \%)$ \\
\hline Male & $46(24.9 \%)$ \\
\hline \multicolumn{2}{|l|}{ Age in years } \\
\hline Mean (standard variation) & $28.8( \pm 13.3)$ \\
\hline Minimum & 3 \\
\hline Maximal & 69 \\
\hline Less 18 years & $47(25.4 \%)$ \\
\hline $18+$ years & $138(74.6 \%)$ \\
\hline \multicolumn{2}{|l|}{ Schooling } \\
\hline In school & $37(20 \%)$ \\
\hline 1 to 8 years & $56(30.3 \%)$ \\
\hline $9+$ years & $92(49.7 \%)$ \\
\hline \multicolumn{2}{|l|}{ Symptoms } \\
\hline Depression/Anxiety & $77.2 \%$ \\
\hline Pain & $84(45.4 \%)$ \\
\hline Limb weakness or paralysis & $185(100 \%)$ \\
\hline Imbalance & $41(22.2 \%)$ \\
\hline Tremors & $23(18.9 \%)$ \\
\hline Dystonia & $5(2.7 \%)$ \\
\hline Sensitive changes & $101(54.6 \%)$ \\
\hline Dizziness & $39(29 \%)$ \\
\hline Blackout episodes & $36(19.5 \%)$ \\
\hline Migraine & $67(36.2 \%)$ \\
\hline Bladder complaints & $54(29.2 \%)$ \\
\hline \multicolumn{2}{|l|}{ Onset disability } \\
\hline Onset less than 24 hours & $108(58.4 \%)$ \\
\hline Onset less than 30 days & $24(13 \%)$ \\
\hline Onset $30+$ days & $53(28.6 \%)$ \\
\hline \multicolumn{2}{|l|}{ Locomotion } \\
\hline Wheelchair-bounded & $44(23.8 \%)$ \\
\hline Ambulatory only inside home & $33(17.8 \%)$ \\
\hline Ambulatory & $89(48.1 \%)$ \\
\hline Dependent of caregiver & $33(17.8 \%)$ \\
\hline One walking stick & $29(15.7 \%)$ \\
\hline Two walking sticks & $10(5.4 \%)$ \\
\hline Walker & $4(2.2 \%)$ \\
\hline
\end{tabular}


marked improvement, $6.5 \%$ had periods of improvement and worsening, and $2.7 \%$ had worsening. There were no demographic differences between those who improved and did not improved.

In addition to the $45.5 \%$ of patients who had pain as initial symptom, $39.5 \%$ complained about pain during followup. Another etiology for the symptoms was not found in any of the 185 patients.

Patients with acute evolution of symptoms ( $<24$ hours) seemed 12x more likely to improve than those with a slow evolution of symptoms (chi-square 12.1). Mental health monitoring appeared to be a relevant variable in the improvement process $(\mathrm{p}=0.02)$. Patients who participated in a rehabilitation program were five times more likely to be cured than patients who did not participate in a rehabilitation program (Table 2).

Among 129 patients who received rehabilitation, 70.5\% had partial (50\%) or marked (75\%) improvement and, from those, $36,2 \%$ had complete remission of symptoms (Table 3).

Of the 47 patients younger than 18 years of age, 35 participated in rehabilitation, and, of these, 26 had complete remission of symptoms. Only one younger patient did not improve after rehabilitation (Table 3 ). Children younger than 18 years old improved significantly more than adults and chronic mFND patients $(\mathrm{p}<0.001)$.

Children and adults who improved and healed did so primarily in the first six months of rehabilitation, with younger patients tending to improve faster than adults. Among these, the remission of symptoms was achieved within 1.6 month of treatment on average, while for adults it happened within 4.4 months of treatment on average $(\mathrm{p}=0.04)$.

Patients with history of blackouts, altered sensitivity $(\mathrm{p}=0.02)$ and associated imbalance $(\mathrm{p}<0.01)$, with evolution of symptoms lasting more than a year $(p<0.01)$ and with lower urinary tract dysfunction $(\mathrm{p}=0.02)$ had a worse prognosis.

\section{DISCUSSION}

Over the last two decades, we have seen increasing recognition of $\mathrm{mFND}^{11}$. In the SARAH unit of Belo Horizonte, although growing, the number of patients remain small, but representative. Those patients challenge knowledge in various stages of the rehabilitation process: diagnostic investigation, problem communication, and treatment.

This study presents a large number of patients from the same unit who were followed up by a multidisciplinary team, some for years. The sample is heterogeneous with respect to age, which allows for comparison between children and adults.

It is noteworthy that, after initiation of rehabilitation, an organic etiology for the symptoms was not found in any of our patients. The literature points out that $4 \%$ of patients

Table 3. Outcome of 129 patients with mFND after rehabilitation.

\begin{tabular}{lcccc} 
& \multicolumn{4}{c}{$\mathrm{n}(\%)$} \\
\hline No improvement & \multicolumn{5}{c}{$\begin{array}{c}91(29.5 \%) \\
(70.5 \%)\end{array}$} \\
Improvement & $\begin{array}{c}\text { [Completely recovered from all symptoms } \\
\mathrm{n}=33(36.2 \%)]\end{array}$ & \\
\hline $\begin{array}{l}\text { Improvement } \\
\text { after rehab }\end{array}$ & $\begin{array}{c}\text { Age under } \\
18 \text { years }\end{array}$ & Age 18+ chi-square & p-value \\
\hline No & 1 & 37 & 16.3 & $<0.0001$ \\
Yes & 34 & 57 & & \\
\hline
\end{tabular}

Table 2. Outcome of 185 patients with mFND.

\begin{tabular}{|c|c|c|c|c|}
\hline & $\mathrm{n}(\%)$ & & & \\
\hline No improvement & $83(44.9 \%)$ & & & \\
\hline Improvement & $\begin{array}{c}101(55.1 \%) \\
\text { [Complete recovery of all symptoms } n=39 \\
(21.2 \%)]\end{array}$ & & & \\
\hline \multicolumn{5}{|l|}{ Rehabilitation } \\
\hline No & $56(30.3 \%)$ & & & \\
\hline Yes & $129(69.7 \%)$ & & & \\
\hline Improvement & Rehabilitation No & Rehabilitation Yes & $95 \% \mathrm{Cl}$ & chi-square $p$-value \\
\hline No & 46 & 38 & \multirow{3}{*}{$11.01(4.9-23.5)$} & \multirow{3}{*}{$<0.0001$} \\
\hline \multirow[t]{2}{*}{ Yes } & 10 & 91 & & \\
\hline & 56 & 129 & & \\
\hline Improvement & Age under 18 years & Age 18+ & $95 \% \mathrm{Cl}$ & chi-square $p$-value \\
\hline No & 7 & 77 & \multirow{2}{*}{$7.2(3.0-17.7)$} & \multirow{2}{*}{$<0.0001$} \\
\hline Yes & 40 & 61 & & \\
\hline
\end{tabular}

95\% Cl: 95\% confidence interval. 
usually has the wrong diagnosis after an average of five years of follow-up ${ }^{5,12}$. Our data is certainly consequence of scientific advances and accurate criteria.

As described in the literature, movement disorders in our population are characterized by a mixed pattern of weakness and sensory disturbance. Many patients also complain of other functional disorders, fatigue, dizziness, and so on. The severity of symptoms is seen as a great disability and renders patients unable to work. The number of people receiving social security benefits reflects the functional and social damage caused by this disease.

Many of our findings confirm the results of other studies. The predominance of females with the disorder is one of them. This might suggest hormonal or genetic specificity related to sex; however, the $25 \%$ prevalence in male patients questions this line of reasoning.

Many patients in our population were in the third and fourth decade of life. The literature indicates that the mean age of onset of symptoms is between 35 and 50 years of age ${ }^{11}$. The cases that involve very young children ( $7 \%$ in children less than 10 years of age), as well as the almost absence of cases in elderly patients are noteworthy.

For the onset of symptoms, almost $60 \%$ of our subjects developed them suddenly, which is within the range described in the literature, between 54 and $92 \%$.

The literature shows a strong association between FND and psychiatric disorders: rates of depression between 20 and $40 \%$ and a rate of anxiety of $38 \% \%^{3}$. In our sample, this prevalence was even greater, providing clear support for the notion that emotional factors are a significant risk factor. All of our patients were referred for mental health services, and those who underwent such treatment improved more than those who underwent only medical and physical therapy treatments. Those who received mental health treatment by psychiatrists and psychologists who were members of the rehabilitation team improved more than patients receiving care from an external service.

Overall, almost $70 \%$ of our patients who participated in the rehabilitation program showed improvements. This result is better than most data presented in the literature, where 66 to $100 \%$ of patients had the same or worse symptoms at follow-up $(\mathrm{n}=135)^{11}$.

The favorable evolution of patients who participated in rehabilitation, all having physical therapy treatment, is similar to the result presented by Nielsen et al. ${ }^{13}$. In their study $72 \%$ of patients with Functional Motor Symptoms who submitted to physical therapy rated their symptoms as improved. Other studies also demonstrate the feasibility of physical therapy as intervention for patients with $\mathrm{mFND}^{14}$.

The better outcome of acute and young patients in relation to chronic patients also confirms the data available in the literature ${ }^{11,15}$, but there are cases where patients with a long-term evolution of symptoms, after beginning rehabilitation, improved rapidly. In our sample, patients who did not improve during the first year of treatment had poorer outcomes compared to those who did.

There is only one published study on lower urinary tract dysfunction in patients with FND. It was a retrospective review of 150 patients diagnosed with definite or probable functional movement disorders between 2006 and 2014 from the National Hospital of Neurology and Neurosurgery in London. We found no studies associating urinary symptoms with the outcomes of FND, but the dysfunction is known to negatively affect quality of life in other neurological disorders ${ }^{15}$. Our study suggests that mFND patients with lower urinary tract syndrome also have worse prognosis than patients without it. Further studies are required to clarify the association between urinary dysfunction and functional neurological disorder.

In contrast to what was previously reported by Nielsen et al. ${ }^{16}$, in our sample, whether patients used locomotion aids was not significant for their outcome. Interestingly, patients who were treated on an inpatient basis, viewing many patients with neurological disorders, did not worsen or present with new symptoms ${ }^{17}$.

The fact that better outcomes were obtained for children compared to adults is an important point. Among children under 10 years old, $80 \%$ had remission of symptoms, and all of them improved. Perhaps the good outcome of our young patients is related to the fact that most of them had close family interventions associated with their psychological and physical treatments. The only patient under 18 who did not improve has been followed up for ten years and is now 27 years old, so far still using a wheelchair.

Motor FND is a highly disabling, daunting public health condition. Treating symptoms early, both in relation to age and onset time, favors positive outcomes. It is assumed that, over time, the mechanisms that underlie the process cause a dysfunctional relationship between mind and body. Good prognosis is related to acute cases, which occur in young individuals who are treated at the beginning of the disease course in a rehabilitation program.

We acknowledge a number of limitations to this work. This study is retrospective, so the variables recorded did not use the some proforma. There is no scale that defines what is "moderate" or "marked" improvement. Also, we have a shorter period of follow-up of those who did not participate in the rehabilitation program; this could have strongly influenced prognostic factors. No participation may suggest patient's refusal in accepting diagnosis, which is known as a main barrier for the treatment of patients with $\mathrm{FND}^{18}$, but may also reflect the "hard to treat" beliefs of the staff. Follow-up was naturalistic, and this may also have influenced prognostic factors. Furthermore, as a rehabilitation hospital, we may have an over-representation of severe cases, and the bias of the over-representation of those who agreed to the treatment. Prospective analysis of rehabilitation interventions and the determinants of their benefits is required to target better outcomes for these patients. 
1. Feinstein A. Conversion disorder. Continuum (Minneap Minn). 2018 Jun;24(3, BEHAVIORAL NEUROLOGY AND PSYCHIATRY):861-72. https://doi.org/10.1212/CON.0000000000000601

2. Espay AJ, Lang AE. Phenotype-specific diagnosis of functional (psychogenic) movement disorders. Curr Neurol Neurosci Rep. 2015 Jun;15(6):32. https://doi.org/10.1007/s11910-015-0556-y

3. Garcin B. Motor functional neurological disorders: an update. Rev Neurol (Paris). 2018 Apr;174(4):203-11. https://doi.org/10.1016/j. neurol.2017.11.003

4. Espay A, Aybek S, Carson A, Edwards MJ, Goldstein LH, Hallett M, et al. Current concepts in Diagnosis and Treatment of Functional Neurological Disorders. JAMA Neurol. 2018 Sep 1;75(9):1132-41. https://doi.org/10.1001/jamaneurol.2018.1264

5. Stone J, Carson A, Duncan R, Coleman R, Roberts R, Warlow C, et al. Symptoms 'unexplained by organic disease' in 1144 new neurology outpatients: how often does the diagnosis change at follow-up? Brain. 2009 Oct;132(Pt 10):2878-88. https://doi.org/10.1093/brain/awp220

6. Stone J, Smyth R, Carson A, Lewis S, Prescott R, Warlow C, et al. Systematic review of the misdiagnosis of conversion symptoms and "hysteria". BMJ. 2005 Oct;331(7523):989. https://doi.org/10.1136/ bmj.38628.466898.55

7. Binzer M, Kullgren G. Motor conversion disorder. A prospective 2-to 5-year follow-up study. Psychosomatics. 1998 Nov-Dec;39(6):519-27. https://doi.org/10.1016/S0033-3182(98)71284-8

8. Crimlisk HL, Bhatia K, Cope H, David A, Marsden CD, Ron MA. Slater revisited: 6 year follow up study of patients with medically unexplained motor symptoms. BMJ. 1998 Feb;316(7131):582-6. https://doi.org/10.1136/bmj.316.7131.582

9. Anderson KE, Gruber-Baldini AL, Vaughan CG, Reich SG, Fishman OS, Weiner WJ, et al. Impact of psychogenic movement disorders versus Parkinson's on disability, quality of life, and psychopathology. Mov Disord. 2007 Nov;22(15):2204-9. https://doi.org/10.1002/mds.21687
10. Heruti RJ, Levy A, Adunski A, Ohry A. Conversion motor paralysis disorder: overview and rehabilitation model. Spinal Cord. 2002 Jul;40(7):327-34. https://doi.org/10.1038/sj.sc.3101308

11. Hallett M, Stone J, Carson A, editors. Functional neurologic disorders. Amsterdam: Elsevier; 2016. (Handbook of Clinical Neurology; 3rd series, v. 139).

12. Gelauff J, Stone J. Prognosis of functional neurologic disorders. Handb Clin Neurol. 2016;139:523-41. https://doi.org/10.1016/B9780-12-801772-2.00043-6

13. Nielsen G, Buszewicz M, Stevenson F, Hunter R, Holt K, Dudziec M, et al. Randomized feasibility study of physiotherapy for patients with functional motor symptoms. J Neurol Neurosurg Psychiatry. 2017 May;88:484-90. https://doi.org/10.1136/jnnp-2016-314408

14. Jordbru A, Smedstad LM, Klungsøyr O, Martinsen EW. Psychogenic gait disorder: A randomized controlled trial of physical rehabilitation with one-year follow-up. J Rehabil Med. 2014 Feb;46(2):181-7. https://doi.org/10.2340/16501977-1246

15. Batla A, Pareés I, Edwards MJ, Stamelou M, Bhatia KP, Panicker $J N$. Lower urinary tract dysfunction in patients with functional movement disorders. J Neurol Sci. 2016 Feb;361:192-4. https://doi. org/10.1016/j.jns.2015.12.048

16. Nielsen G, Stone J, Edwards MJ. Physiotherapy for functional (psychogenic) motor symptoms: a systematic review.J Psychosom Res. 2013 Aug;75(2):93-102. https://doi.org/10.1016/j. jpsychores.2013.05.006

17. Matthews A, Brown M, Stone J. Inpatient physiotherapy for functional (psychogenic) gait disorder: a case series of 35 patients. Mov Disord Clin Pract. 2016 Jan;3(6):603-6. https://doi.org/10.1002/ mdc3.12325

18. Stone J, Carson A, Hallett M. Explanation as treatment for functional neurologic disorders. Handb Clin Neurol. 2016;139:543-553. https:// doi.org/10.1016/B978-0-12-801772-2.00044-8 